\title{
À procura de um imaginário melodramático no século XIX: imprensa, folhetins e romances: da sua produção a sua
}

recepção

\author{
Looking for a melodramatic imaginary in the 19th century: press, leaflets and novels: \\ from its production to its reception. \\ Jean-Yves MOLLIER* \\ Université de Versailles Saint-Quentin-en-Yvelines
}

\begin{abstract}
Resumo: A presença do romance europeu no mundo no século XIX atesta uma forma de mundialização da cultura que se apoia sobre a circulação precoce de jornais, revistas e livros. A leitura quase concomitante de obras de Alexandre Dumas ou de Victor Hugo no Rio de Janeiro, México, Buenos Aires e Paris foi facilitadas pela corrente troca entre os dois continentes. A leitura direta de volumes, mas também a tradução imediata, em castelhano e português produziram formas originais de apropriação desses universos culturais. Os gabinetes de leitura e as associações literárias implantadas no Rio de Janeiro, Belém ou Bahia acompanharam esse vasto movimento de transferência de um imaginário dramático de um lado a outro do Atlântico. Resta, entretanto, tentar encontrar os traços de sua recepção. É com o intuito de propor pistas de pesquisa futuras nesse sentido que se escreveu este artigo.
\end{abstract}

Palavras chave: Romance. Mundialização da cultura. Recepção crítica.

\begin{abstract}
The presence of the European novel in the world in the 19th century attests to a form of globalization of culture based on the early transatlantic circulation of newspapers, magazines and books. The almost simultaneous reading of the works of Alexandre Dumas or Victor Hugo in Rio de Janeiro, Mexico City, Buenos Aires and Paris was facilitated by the flow of exchanges between the two continents. The direct reading of the volumes, but also the immediate translation, into Spanish and Portuguese, have led to original forms of appropriation of these cultural universes. Reading firms and literary associations based in Rio, Belem or Bahia have accompanied this vast movement of transfer from a melodramatic imagination from one side of the Atlantic to the other. However, it remains to try to find the traces of their reception and it is to propose avenues of research for the future that this article focuses on.
\end{abstract}

Keywords: Novel. Globalization of culture. Critical reception.

\footnotetext{
* Professor Emérito de História Contemporânea na Universidade de Paris Saclay/Versailles SaintQuentin-en-Yvelines. E-mail: jean-yves.mollier@uvsq.fr
}

Revista Moara, n. 52, jan-jul 2019 ISSN: 0104-0944

Recebido em 30/04/2019

Avaliado em 09/05/2019 


\section{Introdução}

A onipresença do romance mais ou menos no mundo inteiro foi observada há muito tempo, como bem assinalou Franco Moretti que elaborou seu atlas a partir de um ensaio de quantificação dos traços deixados por este gênero literário nas bibliotecas e nos jornais (MORETTI, 2003). Ele também confirmou a dominação do romance francês sobre seus concorrentes e mostrou que Alexandre Dumas e Eugène Sue foram, com Charles Dickens, os autores mais exportados nos anos 1850-1880. Para quem trabalhou um pouco com essas questões, o fato de os operários da indústria de tabaco La Havane terem atribuído à sua melhor variedade de cigarro o nome de «Montecristo », e do hospital de crianças encontradas em Montevideo ter recebido o nome de Alexandre Dumas, são um índice de sua popularidade incontestável na América Latina e na Europa. A publicação de Montevideo ou a Nova Troia, em 1850, pareceu uma legitimação da luta dos moradores do Uruguai contra seus vizinhos argentinos e compreende-se porque Garibaldi, então presente nesta região do mundo, apelará ao romancista para ajudá-lo na Expedição chamada dos «Mil», ocorrida na Sicília em 1860 (MOLLIER, 2008).

O fato dos leitores franceses dos Mistérios de Paris publicados em folhetins no Jornal dos Debates em 1842-1843 considerarem Eugène Sue como um reformador social e o elegerem deputado socialista de Paris em 1850 demonstra a que ponto o imaginário dos leitores do tempo estava moldado por representações melodramáticas que poderiam levá-los a misturar realidade e ficção. A correspondência trocada entre os leitores desse grande romance-folhetim e o autor projeta uma visão crua sobre fantasmas que percorriam o espírito de boa parte deles (GALVAN, 1998). Na intenção de tomá-lo pelo príncipe Rodolfo ou ao menos pedir-lhe para ajudá-los a resolver a questão social que atormentava a opinião pública naqueles anos, eles fizeram desse homem das letras, burguês ao estilo dândi, amante do luxo e de cavalos, um escritor cada vez mais engajado e, pode-se dizer, um Representante do povo na Assembleia Nacional. Exilado no golpe de Estado de 2 de dezembro de 1851, morreu fora da França em 1857 e seu último livro, Os Mistérios do povo, foi condenado à destruição nesse mesmo ano. Poderíamos fazer observações semelhantes em relação à Alexandre Dumas, 
exilado financeiro em Bruxelas em 1852, mas deportado para o campo republicano e socialista pelos assinantes do seu jornal, O Mosqueteiro, e, em 1860-1861, tornado, ao lado de Garibaldi, o herói da Itália na luta pela sua unificação (DUMAS, 2010).

Esses poucos exemplos dizem muito sobre a capacidade da «literatura melodramática », de acordo com a expressão feliz de Peter Brooks (1976), de se exportar no mundo e transcender as fronteiras. Aproveitando-se a princípio da emergência da imprensa e de sua parte reservada aos folhetins literários e, depois, do sucesso obtido pelos Cabinets de lecture, Circulating Libraries, e outros Gabinetes de leitura ou Grêmios literários que se multiplicaram por toda parte, na Europa e na América Latina, no século XIX, e, enfim, da presença de grandes livrarias nas cidades, o romance se impôs como o gênero mais apropriado da época. Enquanto a poesia contribuiu muito para consagrar a figura do homem de letras como um novo mago, ou um grande sacerdote, um oráculo, por volta de 1820-1830 - pensemos em Byron na Inglaterra, em Lamartine ou no jovem Hugo na França! - o romance deu continuidade à esta última data. Pode-se confirmar isto em Manzoni, poeta e dramaturgo italiano, que se impõe realmente com seu romance, Os Noivos, amplamente inspirado em Walter Scott, ou em Victor Hugo, cujo sucesso com Notre-Dame de Paris, em 1833, o levará a privilegiar esse gênero, ainda que ele tenha iniciado com a poesia e tentado revolucionar o teatro criando Hernani em 1830. Considerada pela polícia parisiense como a obra mais «socialista » de todos os tempos, Os Miseráveis farão de seu autor, a partir de 1862, uma espécie de defensor universal dos humildes e dos oprimidos.

Se Cosette, Marius e Jean Valjean são considerados ainda hoje como verdadeiros tipos sociais, isto não se deve unicamente às adaptações cinematográficas que foram feitas do romance, mas também a sua exportação e tradução pelo mundo inteiro. $\mathrm{O}$ mesmo aconteceu com A Cabana do Pai Tomás, em 1851, um outro best e long-seller difundido inicialmente em folhetim e depois publicado em volumes e traduzido na maior parte das línguas do mundo (PARFAIT, 2007). Reproduzido em múltiplos suportes, chales, garrafas de cerveja, copos etc., adaptado para o teatro e musical, o bravo Pai Tomás fez a volta ao mundo em alguns meses. Ele deveria ilustrar a globalização da cultura que era uma realidade incontestável nos anos 1840-1850, enquanto o vapor ainda não havia se estabelecido nas linhas marítimas transatlânticas. Os barcos à vela gastavam dois meses para chegar à América saindo da Europa, mas 
esse tempo não era um obstáculo para a circulação da moda e leituras. Na verdade, livrarias e proprietários de jornais latino americanos encomendavam de Paris, Londres, Lisboa ou Madri livros e revistas suscetíveis de serem vendidos rapidamente. Os irmãos Garnier de Paris haviam criado duas sucursais, Garnier Hermanos e Garnier Irmãos, para penetrar no México, Argentina e Brasil, e outras livrarias se instalaram para aproveitar o crescimento econômico advindo da formação de um imaginário melodramático comum aos dois continentes (MOLLIER, 2018).

\section{Produção, circulação e recepção do folhetim romanesco}

Todos os trabalhos realizados por especialistas a respeito das relações entre literatura e cotidiano, como Marie-Eve Thérenty (2014) e Alain Vaillant (2001) na França, confirmam a importância do romance-folhetim para o conjunto do século XIX, e, inicialmente, para a primeira metade. Antes de ocorrer a redução sensível do preço médio da compra de um livro de trezentas e cinquenta páginas impressas em formato clássico - a formatação in-18 dos anos 1850, aproximadamente 18 centímetros sob 11,5 - e de surgir uma rede de bibliotecas populares digna deste nome, foi o gabinete de leitura que permitiu colocar os livros e a impressa à disposição de leitores economicamente menos favorecidos (MOLLIER, 2015). Antes de 1815, apenas os aristocratas e a grande burguesia podiam ter obras de Jane Austen. Os romances de

Walter Scott, por exemplo, tiveram dificuldade de distribuição, devido ao alto preço de compra de cada um dos três volumes de Quentin Durward ou de Ivanhoé. A fragmentação das obras em três volumes, de acordo com os procedimentos de corte e branqueamento, permitirá resolver em parte a dificuldade e fará a felicidade das Circulating Librairies que tirarão proveito disso para alugar simultaneamente a três assinantes os três volumes de cada romance. Entretanto, todas as pesquisas sociológicas realizadas nas instituições de leitura britânica são formais: apenas as camadas relativamente altas da população britânica frequentaram a Charles Mudie's Circulating Library de Londres, a mais célebre na época, ou a dos seus concorrentes (CLAIR, 2004; ALTICK, 1998). Na França por outro lado, a concorrência encontrada pelo sistema editorial nacional diante da contrapartida belga levou um empresário editor, Gervais Hélène Charpentier, a conceber, já em 1838, o pequeno volume portátil, o «formato Charpentier » como ele será chamado. Vendido a um preço razoável, 3 F 50, e contendo

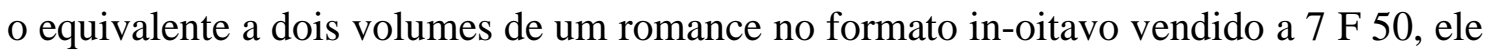
dividia por quarto o preço de compra de um livro. Copiado por Michel Lévy que propõe, em 1846, as Obras completas de Alexandre Dumas pai vendidas a $2 \mathrm{~F}$ o 
volume, o preço se estabilizará em um franco entre 1853 e 1855, datas da comercialização da «Biblioteca dos caminhos de ferro» de Louis Hachette e da «Coleção Michel Lévy » por um franco ou cinco euros atuais (MOLLIER, 2015). Como pode-se mesurar concretamente, a França acabava de demonstrar que se poderia dividir por quinze o preço do lançamento de um romance comum, na condição de aumentar consideravelmente a tiragem dos exemplares, passando de 800 ou 1.000 exemplares em 1835, à 2.500 exemplares em 1838, e 6.600 em 1855. Se compararmos os dois sistemas editoriais, britânico e francês, percebe-se claramente a diferença entre o universo do three ou triple decker de um lado do Canal, e o outro do livrinho de bolso compacto que agradará leitores cada vez maiores do outro lado da Mancha.

Antes que a livraria propriamente dita decole no segundo Império (1852-1870) e recupere a clientela das salas de leitura, cada vez menor, graças a essa baixa considerável do preço de compra dos romances, este encontrou um novo refúgio instalando-se no « rodapé do cotidiano », de acordo com a linda fórmula de Anne-Marie Thiesse (2000). Durante muito tempo se procurou compreender essa migração do gabinete de leitura para o jornal, mas as razões são antes de tudo econômicas e jurídicas. No ponto de partida da mudança da fórmula dos jornais, uma reforma postal aumentaria o preço dos jornais utilizando os serviços dos Correios. Essa medida de 1827 obrigou os proprietários dos títulos mais lidos a procurar meios para não repercutir sobre o assinante esse aumento de tarifas. É a integração de duas novidades, a abertura da quarta e última página do jornal à publicidade comercial e a publicação de romances chamados de novidade que permitirá resolver a equação aumentando sensivelmente o número de assinantes. Em 1836, dois jornais passaram juntos o Rubicon, isto é, dividiram em dois o preço da assinatura anual (40 F ao invés de $80 \mathrm{~F}$ ), La Presse, de Emile de Girardin, e Le Siècle de Dutacq (KALIFA, 2011). O primeiro é o mais conhecido, mas é o segundo que publicará a maioria dos grandes romances de Alexandre Dumas pai. Após publicá-los na rubrica «folhetim », isto é, um espaço jornalístico até então reservado à crítica literária ou dramática, Armand Dutacq reunirá esses «folhetins » de um novo gênero em um suplemento chamado Museu do Século, distribuído gratuitamente aos novos leitores que faziam uma assinatura ou que a renovavam (WITKOWSKI, 1997). 
As pessoas se dirigiam, sem sabê-lo, e tateando, a essas publicações de vinte cêntimes que eram chamadas pelos contemporâneos de « romance à quatre sous » (MOLLIER, 2008) - um sou valia cinco centimes - em 1848-1851. Os escritores acabavam de descobrir no folhetim de imprensa, já bastante difundido, seja na parte de «variedades», no interior do jornal, seja embaixo da primeira página, no espaço reservado ao « folhetim »uma fonte quase inesgotável de recursos financeiros. Balzac, como Dumas pai e outros, Eugène Sue, Paul Féval, Emile Souvestre, para esta primeira geração, os Ponson du Terrail e outros, Gustave Aimard e Edmond About da segunda geração não hesitarão para aumentar os volumes de A comédia humanapublicados após1838. Esplendores e misérias das cortesãs é uma magnifica ilustração daquilo que deveria causar um terremoto. A crítica literária se enfurece, e um dos seus maiores representantes, Augustin Sainte-Beuve, condenaa «literatura industrial» em um artigo fulminante na Revista dos Dois Mundos de setembro 1839. Depois dele, os parlamentares atacaram o romance folhetim em série, porque o gênero literário que explorava sistematicamente os recursos da literatura melodramática nasceu exatamente nessa época, e se viu, na Câmara dos Deputados, o barão Chapuys-Montlaville combater violentamente estes livros ruins, que corrompiam a juventude e até moradores dos lugares mais afastados. $\mathrm{O}$ combate será vencido quando, em julho de 1850, um outro deputado, católico, conservador e monarquista, colocará em votação um imposto sobre os romances que circulavam pela imprensa, a famosa «emenda Riancey » que o fez ficar para a posteridade (DUMASY, 1999). Reveladoras dos fantasmas das elites civis e religiosas, essas fobias traduziam uma recusa da profunda penetração do romance no espaço social, e a dificuldade de admitir as consequências da alfabetização em massa, a saber a possibilidade oferecida a todos os franceses que possuíssem algumas moedas de gastá-las com lazer. O aparecimento dos « romances à quatre sous » em 1848 levaria ainda mais longe a divulgação em massa já que as Obras completasilustradas de Victor Hugo, Alexandre Dumas, Eugène Sue e George Sand recebiam tiragens de vinte mil exemplares amplamente distribuídos fora das redes habituais da livraria ou do gabinete de leitura. Presentes nos salões de beleza e distribuidores de bebida frequentados pela clientela dos artesãos e proletariados, esses sinais de uma autêntica aculturação das classes pobres surpreendem as autoridades que tomam medidas policiais para proibir a comercialização das brochuras. Trata-se de impedir a propaganda socialista, e isto, com o risco de arruinar os pequenos editores que eram especialistas nessa literatura de grande circulação e de grande consumo, a qual podemos seguramente chamar de «popular » sem dúvida alguma (MOLLIER, 2008, p. 83-97). Estudar a produção, a circulação e a recepção de romances folhetins permite portanto penetrar no interior do sistema policial e ainda ver a instituição judiciária, a instituição parlamentar, ou as Igrejas e as associações de defesa da família 
se mobilizarem para tentar se opor à onda que leva tudo por onde passa. Ela conduz a Igreja católica a encorajar a escrita de romances edificantes destinados a neutralizar as ficções e dramas que ela joga no inferno do Index. Na impossibilidade de afastar o fiel da leitura e do sonho, apesar da censura oficial de Balzac, Dumas, Flaubert, Hugo, Sand, Stendhal ou Sue, ela prefere buscar derivados - é a base da literatura edificante e incitar os escritores que reclamam da sua mensagem a publicar «bons » romances (MOLLIER, 2014). O editor Alfred Mame de Tours se especializou neste gênero, Lefort em Lille, Ardant e Barbou em Limoges, Mégard em Rouen, Périsse em Lyon e alguns outros profissionais que publicaram, entre 1830 e 1880, milhares de títulos que ninguém mais lê, mas cujos catálogos são testemunhas preciosas dessa tendência (ARTIAGA, 2007). Uma obra romanesca subsiste nesse rio de « chá literário », como o qualifica o editor Pierre-Jules Hetzel, Fabiola ou a Igreja das catacumbas, romance redigido pelo cardeal Wiseman e traduzido em várias línguas após sua edição em 1854. Quanto às dezenas de ficções publicadas por Just-Jean-Etienne Roy, um dos autores estrela da casa Mame (BOULAIRE, 2012), elas foram também tão efêmeras quanto a borboleta noturna, mas tinham seu público, como o cônego Schmid, autor alemão traduzido em francês e, a partir desta língua, em espanhol ou português, ou ainda estas várias mulheres que seus irmãos confrades qualificavam com desprezo de «letradas » e que produziam essa « literatura para governantas » que fustigava o editor de Jules Verne.

\section{Tradução e circulação internacional do romance}

A observação atenta dos romances ingleses que circularam no Rio de Janeiro no século XIX permitiu à Sandra Guardini Teixeira Vasconcelos evidenciar um determinado número de fenômenos que podemos sem dúvida generalizar e transportar, ao menos em parte, para Belém, São Luis do Maranhão ou Recife, todas cidades que abriram gabinetes de leitura ou círculos literários nos anos 1850-1880. Dos 502 títulos escritos por 99 autores, apenas 225 tinham sido comercializados na sua língua original, o inglês, enquanto que 146 outros eram transmitidos em francês, 128 em português e somente 3 em espanhol (VASCONCELOS, 2008). Essas precisões confirmam em grande parte as análises de Franco Moretti, e o que sabemos da importância da língua francesa como língua de cultura predominante até 1914. Outros números confirmam a forte presença na América Latina dos livros e jornais impressos na França, tanto em 
francês quanto em espanhol e português. Uma parte importante destes volumes partia para o México, primeiro importador do século XIX, Brasil, segundo em toneladas, Colômbia, Argentina e Chile, todos países presentes durante todo o período nas estatísticas alfandegárias e do Ministério do Comércio, fontes preciosas para o observador (GODECHOT;MARSEILLE, 1997, p. 373-382).

Essas duas séries arquivísticas confirmam a exportação concomitante de livros e de revistas impressas em francês e nas duas línguas utilizadas na América Latina durante todo o período que precedeu a Primeira Guerra Mundial. Para citar apenas um dado numérico, correspondente ao último ano de paz, 1913, o México havia recebido 1783 quintais métricos de impressões vindas da França, 1278 do Brasil, 1034 da Argentina, 912 da Colômbia e 896 do Chile. Se acrescentarmos a esses dados os números das impressões em língua espanhola e portuguesa, e que partiam dos portos franceses para o continente latino americano, encontraremos ainda 1162 quintais métricos expedidos para a Argentina, 490 para o Brasil, 484 para o México, 466 para o Chile e 207 para a Colômbia. Ao todo, essas exportações de produtos culturais e didáticos representavam $13 \%$ das exportações francesas às vésperas do primeiro conflito mundial. Essas remessas de mercadorias correspondiam a milhares de navios, navegando em território nacional ou estrangeiro, e procurando no Havre, Bordeaux ou Marselha, centenas de milhares de volumes destinados ao mercado que se estendia do sul dos Estados Unidos à Terra do fogo ( GODECHOT; MARSEILLE, 1997, p. 373382).

Outro exemplo permite medir a importância do conhecimento das rotas marítimas para o pesquisador em ciências sociais e o especialista de literatura comparada que quer compreender os mecanismos empreendidos nesta globalização da cultura que não devia nada à internet nem ao arquivo numérico. Trata-se de um periódico impresso em Paris para um negociante que morava em Havana e que circulou na América Latina de 1842 a 1886, O Correio de além mar. Essa revista reproduzia, em francês e em espanhol, a maioria dos romances recém publicados em Paris, quer fosse Capitão Paulo ou o Conde de Monte-Cristo de Dumas pai, e informava sobre as novas tendências da moda aproximando os dois espaços políticos e culturais. Se acompanharmos as vias empreendidas pelos barcos que transportavam esse periódico, 
perceberemos que eles atracavam primeiro em Havana e em Granada, Antilles, Charleston na Luziânia, Vera Cruz, de onde os pacotes partiam para o México, para a América do Norte, antes de ir ao Rio de Janeiro, Montevideo, Santiago do Chile, Valparaíso, Arequipa, Lima, Bogotá, San Salvador e Caracas no sul do continente. Os mesmos barcos não faziam a totalidade deste circuito e um bom número transbordava antes que o conteúdo das cargas alcançasse os portos onde $O$ Correio de além mar e seus concorrentes distraíam correspondentes responsáveis por divulgar naquelas terras os ecos do Velho Mundo (MOLLIER, 2008).

Trabalhando no Grêmio Literário e Recreativo Português de Belém, fundado em 1846 por negociantes desejosos de conservar uma forte ligação com sua antiga pátria, Valéria Augusti mostrou que os circuitos de provisão eram diferentes daqueles já mencionados e que em Belém do Pará, às portas da Amazônia, foram as livrarias portuguesas de Lisboa ou do Porto que expediram os carregamentos de livros e de jornais destinados à clientela local (AUGUSTI, 2013). Em outros lugares, por exemplo no Chile, foram essencialmente livrarias londrinas que dominaram estas trocas também com Madri, Cadix ou Sevilha para uma parte da América Espanhola. As rotas marítimas eram portanto variadas e é indispensável ler os jornais reproduzindo anúncios comerciais e publicados nos portos da América Latina para encontrar pistas, indícios, como diz Carlo Ginzburg (ANO), das trocas e transferências culturais que implicavam os dois rios dos Oceano Atlântico. As estradas terrestres são bem menos conhecidas, mas vias fluviais, como o Amazonas, de Belém à Manaus, e a cabotagem entre os portos, de Belém à São Luis do Maranhão, Fortaleza, Natal e Recife, ou do Rio de Janeiro à Bahia de um lado e Santos do outro, representaram um papel considerável nestes movimentos. Aqui também, a leitura da imprensa e o exame dos cartazes e outros anúncios de vendas e os leilões de mercadorias informam sobre transferências culturais comercializadas e limitam mais precisamente os trajetos Europa América, entretanto menos sobre o retorno dos navios que transportavam livros e revistas do Novo Mundo, à medida que a impressão local substitui papeis impressos na Europa.

Valeria Bezerra (2018), que se interessa por traduções de romances franceses efetuados, após 1870, pelo grande livreiro editor do Rio de Janeiro, Baptiste-Louis Garnier, confirmou as conclusões de Cláudia Neves Lopes (ANO) apresentadas em sua 
tese de doutorado em literatura sobre esse livreiro estabelecido no Brasil. Para ela, foi o brasileiro Garnier que institucionalizou de alguma forma a literatura desse país, pagando escritores e tradutores locais por uma atividade que naquele momento tinha reconhecidamente um status social (LOPES, 2001). Examinando as capas dos romances franceses traduzidos em português e publicados por B.L. Garnier no Rio de Janeiro, Valeria Bezerra (2018) descobriu um fenômeno exemplar desse movimento de emergência de uma literatura nacional, o fato de que o nome do tradutor brasileiro fosse impresso em grandes letras, acima do título, e que o nome do autor nem sempre aparecia na capa (BEZERRA, 2018). Podemos aproximar esse desvio de um outro fenômeno, de renacionalização dos escritores franceses mais conhecidos na América Latina, observado e analisado por Jean-François Botrel. O pai do Conde de Montecristo tornou-se, em muitas capas, Alejandro Dumas, e não mais Alexandre, e os leitores imaginavam sem dúvida que Pablo Féval escondia um Paul Féval francês e Eugenio Sue um autor que morava do outro lado do Oceano Atlântico (BOTREL, 2001). O mesmo acontecerá com Julio Verne, autor fetiche das edições Hetzel com capas vermelhas e ouro, precisamente traduzido, sem o consentimento dos direitos autorais, na coleção de Baptiste-Louis Garnier.

Seria necessário acompanhar as rotas empreendidas pelos maços de livros eróticos que os irmãos de Baptiste-Louis, Auguste, Hippolyte e Pierre Garnier, haviam colocado à venda até 1848 em Paris e que eles pararam de comercializar na França para escapar da prisão, mas que reciclaram alegremente na América Latina (MOLLIER, 2010, p. 321-337). Temos a prova dessas trocas graças aos arquivos policiais franceses que contém a lista de uma parte de tais obras. Encontramos grandes romances do Marquês de Sade, Justine ou a virtude, mas também títulos pertencentes à esta literatura «filosófica » que Robert Darnton desvendou por tantos trabalhos, e de obras que não deixaram nenhum traço na memória (DARNTON, 1983). Apesar dos nossos encorajamentos, os pesquisadores brasileiros não recuperaram, até aqui, determinados exemplares desses livros nas bibliotecas particulares, mas é provável que os descubramos, logo que os algoritmos poderosos permitam «colher » resultados dos Big data que vão alimentar a pesquisa nos próximos anos, revolucionando nossas maneiras de trabalhar. Gallica, na França, Europeanea na Europe, a Biblioteca eletrônica de Quebec no Canadá, e, evidentemente, a Digital Public Library of America, adorada de 
Robert Darnton, e já enriquecida por mais de vinte milhões de objetos numéricos, vão revolucionar os métodos de trabalho e vão levar equipes internacionais a horizontes sem dúvida despercebidos até aqui.

É provável que as novas gerações demonstrem algum desrespeito pelos trabalhos dos seus precursores e vemos se desenhar um movimento de rejeição ou de questionamento das conclusões tiradas dos pioneiros da utilização de métodos quantitativos em literatura comparada ou em história cultural. Um pesquisador britânico talentoso, trabalhando na Universidade Western Sydney na Austrália, Simon Burrows, especialista em Iluminismo mas também em humanidades numéricas, disponibilizou no sistema on line os arquivos da Sociedade Tipográfica de Neuchâtel na qual trabalhou Robert Darnton (2017) e questionou a abordagem de suas análises mostrando que alguns títulos destacados pelo historiador americano jamais foram impressos e que, de qualquer forma, a presença do livro religioso ultrapassava de longe a do livro erótico nas suas avaliações anuais (ANDRESS, D.;BURROWS, S., 2015). Haja o que houver, essas polêmicas que lembram a querela dos Antigos e dos Modernos é presente em todas as épocas, podemos adivinhar, por meio desse exemplo, o que os Big Data e os "colhedores de computadores", esse agrupamento de milhares de computadores que se assemelham às grandes estações de máquinas agrícolas que anunciaram uma revolução nas formas de produzir alimentos no início dos anos 60, trazem consigo. (TEBOUL; AMRI, 2014). À serviço das pesquisas em Ciências Sociais, estas montanhas de dados brutos permitem sobretudo medir a frequência da aparição de um título em um longo período - um século - e desenhar curvas às vezes inesperadas e sempre surpreendentes.

Essas indicações em números, que parecem um pouco com eletrocardiogramas, dão uma ideia das frequências de utilização, o que já era o caso dos números de tiragem ou do número de reimpressões e reedições, que convém não confundir, ainda que elas permaneçam, no momento, relativamente difíceis de manusear, devido à falta de dados numéricos suficientes. Quando todos os computadores estiverem interconectados e que pudermos deixar as máquinas fazer os cálculos sem que haja necessidade de uma intervenção humana, é provável que os mapas do continente literário que sairão desse mainstream de um novo gênero surpreenderão seus leitores em razão das terras que eles farão emergir e dos continentes que eles engolirão (BASTIN;TUBARO, 2018). Contudo, a pesquisa científica é assim, e cada época define suas ambições, seus 
horizontes de expectativa e os métodos que decorrem disto. Não faz muito tempo, a Sorbonne só jurava com o texto de uma obra, recusando obstinadamente as lições da bibliografia material como as do pesquisador britânico de origem neozelandesa, Donald F. McKenzie, desenvolvidas em Oxford (McKENZIE,1986). Hoje, ninguém mais pode negar que as formas produzem sentido e que não se lê mais um romance da mesma maneira em uma edição de luxo, impressa em papel bonito ou, ao contrário, em livro de bolso destinado a terminar em uma lixeira. Nós experimentamos com nossos estudantes: nenhum deles ousa escrever o que quer que seja nas margens de um bonito volume da «Biblioteca da Pléiade », a coleção farol da editora Gallimard de Paris, impressos em papel Bíblia, um papel indiano de alta qualidade e muito agradável ao tocar. Os mesmos «cobaias » reconhecem que rascunham seus livros de bolso, dobram as páginas, e levam estes volumes para a praia ou montanha, o que eles não fariam com uma edição rara.

Entramos aqui no universo do fetichismo, da coleção, da fantasia, e seria útil convocar psicólogos, ou psicanalistas, para progredir no estudo dos mecanismos psíquicos da obra no campo das coleções. Ainda que se trate, para o editor, de fidelizar a clientela e de persuadir os compradores de um volume indispensável para completar sua série, o que visa o consumidor que consente com esta estratégia de marketing da qual ele não é exatamente o trouxa? De acordo com os tipos de público, as motivações variam, e sabemos que os leitores mais populares não colecionam livros para exibir sua cultura ou citar suas últimas leituras em conversas destinadas a reforçar seu status social. Para eles, o nome do autor importa pouco e o título da obra não é sempre lembrado como deveria. É a intriga que o sensibiliza no conteúdo do romance e é dela que eles falarão eventualmente com seus pares. A leitura de diários íntimos, das correspondências, as cartas dirigidas aos jornais, as confidências deixadas por livreiros que publicaram suas lembranças ou as dos bibliotecários podem constituir fontes igualmente úteis para avançar na compreensão deste imaginário melodramático que se desenvolve um pouco durante todo o século XIX, mas tomando, sem dúvida, formas e rostos diferentes de acordo com o país e culturas em cada grupo humano.

Restaria tentar descobrir o que um leitor de Belém, comerciante ou artesão, recentemente imigrado da Europa, ou nascido no local, poderia ter em mente ao escolher um título no catálogo de seu Grêmio literário. Aqui também, a procura de 
testemunhos escritos não deve sobrepor à ausência aparente de documentos, mas deve tentar contornar esse obstáculo e encontrar meios engenhososde ultrapassá-los. Quais foram as reações do clérigo católico em relação ao clube de leitura ? Existem ainda pistas dos boletins diocesanos, almanaques locais, arquivos do seminário ou do Bispo? A imprensa, na sua diversidade, guardou a memória de polêmicas do contexto de um título mais ou menos provocador? Sejam quais forem as perguntas colocadas, trata-se de obrigar a fonte aparentemente calada a dizer o que ela não quer deixar vir à tona e cabe ao pesquisador ajudá-lo, talvez até forçá-lo, fazendo emergir fontes desconhecidas porque pouco ou nunca foram solicitadas em uma perspectiva literária.

Sem desenvolver esse ponto, poderíamos indicar a leitura atenta dos almanaques, das canções populares, dos espetáculos de cabaré e musicais, que podem, todos, conservar alguma coisa em relação ao espaço do romance. Os objetos em si, vimos com o exemplo de A cabana do pai Tomás, são às vezes os testemunhos mais eloquentes da moda e da tendência de um romance ou de uma peça de teatro. Ainda é necessário saber interrogar o papel de parede das residências, cuja decoração varia às vezes em virtude das modas literárias, ou cinematográficas mais tarde, os motivos dos aventais, dos xales que vestem as mulheres, copos de bebida oferecidos pelas marcas para garantir a sua publicidade. Os pequenos personagens disfarçados em pacotes de café ou de arroz em uma determinada época para serem guardados pelas crianças detém igualmente uma certa relação com o imaginário literário e devem ser pesquisados, se quisermos ter a certeza de compreender profundamente os mecanismos psicológicos pelos quais a literatura inspira uma sociedade. Teremos compreendido: o espaço literário é infinitamente maior, mais aberto do que aquilo que é reservado apenas à leitura direta das obras. Não seria inútil concluir, após Pierre Bayard, que os livros dos quais melhor falamos não são sempre aqueles que lemos, mas aqueles dos quais ouvimos falar por alguém capaz de colocar uma tamanha emoção, que a ilusão de ter lido o romance substituirá perenemente, e por muito tempo, sua leitura direta ...

\section{REFERÊNCIAS}

ALTICK, Richard D. The English Common Reader. A Social History of the Mass Reading Public, 1800-1900. Colombus: The Ohio State University Press, 1998. 
ANDRESS,D., $\quad$ BURROWS, S. (2015-01-01). Books, Philosophy, Enlightenment. In The Oxford Handbook of the French Revolution. Oxford University $\begin{array}{lllll}\text { Press. } & \text { Retrieved } & 2 & \text { Jun. } & \text { 2019, }\end{array}$ https://www.oxfordhandbooks.com/view/10.1093/oxfordhb/9780199639748.001.0001/o xfordhb-9780199639748-e-005.

ARTIAGA, Loïc Artiaga. Des torrents de papier: catholicisme et lectures populaires au XIXe siècle. Limoges: PULIM, 2007.

AUGUSTI, Valéria. Coleções editoriais de baixo custo e traduções de romances franceses no acervo do Grêmio Literário Português do Pará. Letras, Santa Maria, RS, n. 47, p. 21-36, nov. 2013. DOI: http://dx.doi.org/10.5902/2176148511753. ISSN 21761485. Disponível em:

https://periodicos.ufsm.br/letras/article/view/11753. Acesso em: 02 jun. 2019.

BASTIN, Gilles;TUBARO, Paola. Le moment big data des sciences sociales, Revue française de sociologie, CNRS, 2018, n. 59, v. 3, p.375-394.

BEZERRA, Valéria Cristina. Tradução e literatura nacional: um estudo do empreendimento editorial de B. L. Garnier (1870 - 1880) In: SOUZA, Roberto Acizelo Quelha de; MEDEIROS, Constantino Luz de. A história da literatura como problema: reflexões sobre a crise permanente nos estudos diacrônicos de literatura. Rio de Janeiro: Associação Brasileira de Literatura Comparada, 2018, p. 85-99.

BOTREL, Jean-François. L'exportation de livres et modèles éditoriauxfrançais en Espagne et en Amérique Latine (1814-1914).In: MICHON, J. E MOLLIER, J.-Y. (dir)Les mutations du livre et de l'édition dans le monde du XVIIIe siècle à l'an 2000. Québec: Les Presses de l'Université Laval/Paris: L'Harmattan, 2001, p. 219-239.

BOULAIRE, Cécile (Dir). Mame. Deux siècles d'édition pour la jeunesse.Rennes: PUR, 2012.

BROOKS, Peter.The Melodramatic Imagination: Balzac, Henry James, Melodrama and the Mode of Excess. Yale: Yale University Press, 1976.

DARNTON, Robert. Bohème littéraire et Révolution: Le monde des livres au XVIIIe siècle. Paris: Gallimard/Le Seuil/Hautes Etudes, 1983.

DARNTON, Robert Darnton. A Literary Tour de France. Oxford: Oxford UniversityPress, 2017.

DUMAS, Alexandre.Dictionnaire Dumas. Paris: Editions du CNRS, 2010. 
DUMASY, Lise. La querelle du roman-feuilleton. Littérature, presse et politique, un débat précurseur (1836-1848). Grenoble: Ellug, 1999.

GALVAN, Jean-Pierre. Les Mystères de Paris et leurs lecteurs.Paris:L'Harmattan, 1998. 2 vol.

GODECHOT, Olivier;MARSEILLE, Jacques Marseille. Les exportations de livres français au XIXe siècle. In: MOLLIER, J.Y. (dir.). Le commerce de la librairie en France au XIXe siècle. 1789-1914. Paris: IMEC Editions/Editions de la MSH,1997, p. 373-382.

KALIFA, Dominique, RÉGNIER, Alain, THÉRENTY, Marie-Eve et VAILLANT, Alain. La civilisation du journal. Histoire culturelle et littéraire de la presse française au XIXe siècle. Paris: Nouveau Monde Éditions, 2011.

NEVES LOPES, Cláudia. Les relations éditoriales entre le Brésil et le Portugal: la place du livre et de l'édition dans le processus de la colonisation et de la décolonisation culturel : 1889-1989.Villeneuve-d'Ascq: Presses universitaires du Septentrion, 2001.

McKENZIE, Donald F. Bibliography and the Sociology of Texts. London: The British Library, 1986.

MORETTI, Franco. Atlas do romance europeu. 1800-1900. Sao Paulo: Boitempo, 2003. MOLLIER, Jean-Yves Mollier. Traduction et mondialisation de la fiction: 1'exemple d'Alexandre Dumas père en Amérique du Sud, Vingt-QuatrièmesAssises de la traduction littéraire (Arles 2007). Arles, Actes Sud, 2008, p. 225-238.

MOLLIER, Jean-Yves. Uma livraria internacional no século XIX. A livraria Garnier frères. In:Suportes e Mediadores. A Circulação Transatlântica dos Impressos (17891914). Campinas: Editora Unicamp, 2018, p. 33-53.

MOLLIER, Jean-Yves. Une autre histoire de l'édition française. Paris: La fabrique éditions, 2015.

MOLLIER, J.-Y. A leitura e seu publico no mundo contemporâneo: Ensaios sobre Historia Cultural. Belo Horizonte: Authêntica , 2008.

MOLLIER, J.-Y. La mise au pas des écrivains. L'impossible mission de l'abbé Bethléem au XXe siècle. Paris: Fayard, 2014.

MOLLIER, J.-Y. O Dinheiro e as Letras: história do capitalismo editorial. São Paulo: Edusp, 2010. p. 321-337. 
PARFAIT, Claire Parfait. The Publishing History of Uncle tom's Cabin. 1852-2002. Burlington: Ashgate Publishing Lted, 2007.

ST CLAIR, William. The Reading Nation in the Romantic Period. Cambridge: Cambridge University Press, 2004.

TEBOUL, Bruno;AMRI, Taoufik. Les Machines pour le Big Data: Vers une Informatique Quantique et Cognitive. 2014. hal-01096689v2.

THÉRENTY, Marie-Eve. La Invencion de la Cultura Mediatica. Prensa, Literatura y Sociedad en Francia en el siglo XIX. Mexico: Cuadernos Sequencias, 2014.

THÉRENTY, Marie-Eve;VAILlANT, Alain. 1836: L'an I de l'ère médiatique. Paris:Nouveau Monde éditions, 2001.

THIESSE, Anne-Marie. Le roman du quotidien. Lecteurs et lectures populaires à la Belle Epoque [1984]. Paris, Seuil, 2000.

VASCONCELOS, Sandra Guardini Teixeira. Cruzando o Atlântico: notas sobre a recepção de Walter Scott. In: TRAJETÓRIAS do romance: circulação, leitura e escrita nos séculos XVIII e XIX. Campinas, SP: Mercado das Letras, 2008.

WITKOWSKI, Claude. Les éditions populaires. 1848-1870. Paris: GIPPE, 1997, p. 4063. 